\title{
DESAIN DAN IMPLEMENTASI SISTEM KONTROL PUTARAN MOTOR PADA MESIN CNC LASER DENGAN KONTROL PID
}

\author{
Baghazt Kumara Tunggal \\ Program Studi Teknik Mesin \\ Universitas Muria Kudus \\ Email: baghazttunggal@gmail.com \\ Masruki Kabib \\ Program Studi Teknik Mesin \\ Universitas Muria Kudus \\ Email: masruki kabib@umk.ac.id \\ Akhmad Zidni Hudaya \\ Program Studi Teknik Mesin \\ Universitas Muria Kudus \\ Email: Akhmad.zidni@umk.ac.id
}

\begin{abstract}
ABSTRAK
Sistem kontrol ini bertujuan untuk menghasilkan sistem kendali kecepatan putar motor pada mesin cnc laser cutting sehingga dapat meningkatkan kinerja dari mesin laser ini dan mendapatkan konfigurasi pemotongan yang tepat untuk material akrilik. Metode penelitian yang digunakan adalah dengan menggunakan modul CNC Shield dan Arduino sebagai sistem kendali untuk menguji dan membangun mesin. Proses simulasi, menggunakan software Inskcape untuk mendesain pola atau gambar. Proses verifikasi merupakan proses membandingkan data yang dikonversi dari citra ke bahasa G-code dengan data dokumen.Melalui penelitian ini telah di rancang dan dibuat sistem kontrol kecepatan gerak motor stepper pada mesin CNC laser dengan menggunakan sistem kontrol PID ddengan nilai $\mathrm{P}=85,7095, \mathrm{I}=8786,01, \mathrm{D}=0,2090$ hasil pengujian menunjukkan putaran motor motor stepper menunjukkan kecepatan motor $200 \mathrm{rpm}$ dan didapatkan akurasi putaran motor 200,25 rpm.
\end{abstract}

Kata kunci : G-code, mikrokontroler Arduino, PID

\begin{abstract}
This control system aims to produce a motor rotational speed control system on a cnc laser cutting machine so that it can improve the performance of this laser machine and get the right cutting configuration for acrylic material from testing the cnc laser cutting machine made. The research method used is to use the CNC Shield module and Arduino as a control system to test and build machines. Simulation process flow chart, using Inskcape software to design patterns or images. The verification process is the process of comparing the converted data from the image into the G-coded language with document data.Through this research, it is hoped that a schematic diagram of a laser cutting machine control system can be obtained from the work test data of a laser cutting machine with a 3-axis CNC microcontroller based on Atmega328 Arduino, as well as to produce a laser cutting machine prototype and parameter values. Based on the research, a stepper motor speed control system has been designed and made on a CNC laser machine using a PID control system with a value of $\mathrm{P}=85.7095, \mathrm{I}=8786.01, \mathrm{D}=0.2090$, the test results show the rotation of the stepper motor shows the speed motor $200 \mathrm{rpm}$ and the motor rotation accuracy is obtained $200.25 \mathrm{rpm}$.
\end{abstract}




\section{PENDAHULUAN}

Ilmu dan teknologi termasuk mesin dan eletronika, berkembang pesat seiring dengan perkembangan zaman. Jika dulu sistem kerjanya masih menggunakan tenaga manual dan peran manusia sangat penting, namun sekarang sistem tersebut telah beralih ke sistem otomatis dengan menggunakan robot. Oleh karena itu masyarakat membutuhkan hal-hal yang cepat dan praktis untuk menghasilkan produk, oleh karena itu perlu adanya dukungan dan ketersediaan alat.[1]

Mesin CNC adalah istilah yang digunakan untuk mengontrol sistem operasi melalui komputer internal. Karena keakuratan dan efisiensinya, teknologi CNC saat ini merupakan cara terbaik untuk memenuhi produk pasar guna memenuhi kebutuhan pembuatan komponen. Kehandalan peralatan mesin CNC tidak terlepas dari komponen pendukungnya, seperti perangkat keras dan perangkat lunak.

Computer Numerical Control adalah sistem otomatisasi mesin perkakas yang dioprasikan oleh perintah yang diprogram secara abstrak dan disimpan dimedia penyimpanan, hal ini berlawanan dengan kebiasaan sebelumnya dimana mesin perkakas biasanya dikontrol dengan putaran tangan atau otomatisasi sederhana menggunakan cam.[2]

Mesin CNC laser cutting memiliki berbagai keunggulan dibandingkan teknologi manufaktur lainnya karena dapat berjalan dengan baik. Penggunaan mesin CNC pada sistem laser cutting sangat diperlukan, karena dapat memotong suatu bahan atau menggores dengan bentuk desain sesuai dengan yang diinginkan. Pada saat ini sistem CNC hanya memiliki satu fungsi dalam satu sistem. Adapun untuk mengoprasikan $\mathrm{CNC}$ saat ini harus lebih dari satu software seperti halnya CNC plotter. Gambar harus terlebih dahulu dikonversi menjadi G-Code dengan software inkscape dan G-Code dikirim menggunakan Universal G-Code Sender. Sedangkan pada saat ini belum adanya software dalam satu interface, untuk mengendalikan dua sistem CNC. G-Code adalah fungsi untuk memberi tahu mesin untuk berpindah ke berbagai titik dengan kecepatan yang diinginkan.[3]

Penelitian [4] didapatkan dari Mesin Pemotong Laser G-Weike LC6090 pengaturan tingkat operasi standar dengan daftar untuk proses pemotongan dan pengukiran bahan. Ini mengarah ke proses penyiapan memotong mesin ukiran berdasarkan asumsi atau perkiraan saja, produk yang dihasilkan sering kali menjadi kurang berkualitas, prosesnya kurang efisien, dan kemudian berdampak pada masa pakai tabung $\mathrm{CO}_{2}$ laser. [4]

Gagasan penelitian ini adalah merancang bangun mesin laser engraving dua axis dengan menggunakan mikrokontroller berbasis ATMega328 Arduino Nano untuk sistem kontrolnya. Arduino adalah perangkat keras open source yang cukup populer dan mudah diaplikasikan. Arduino akan menerima $G$-code melalui port serial dari $G$-code interpreter yang berjalan pada komputer dan akan memberikan perintah aktuasi ke driver motor stepper dan laser modul. Mekanisme penggerak mesin laser engraving menggunakan motor stepper sebagai aktuator linier pada setiap sumbu X, Y, dan Z [5].

Sistem kontrol gerak untuk motor stepper dengan menggunakan tegangan $5 \mathrm{~V}$ dengan mikrokontroler dapat mengendalikan lead screw saat mesin beroperasi. Sistem kecepatan motor dapat dikendalikan.

Sistem multi CNC yang memiliki dua fungsi dalam satu sistem. Sistem multi CNC dapat membuat grafir laser pada kayu, dan dapat membuat sebuah pola gambar pada kertas dengan menggunakan bolpoin secara otomatis. Sistem multi CNC dioprasikan dengan satu software berbasis LabVIEW. Program dapat mengkonversi gambar menjadi G-Code dan mengirim G-Code ke dalam sistem multi CNC hanya dalam satu interface, sehingga lebih memudahkan dalam mengoperasikan sistem multi CNC tersebut [6].

Pengendalian putaran rol telah dilakukan dengan mengendalikan putara motor stepper pada rol penarik mesin pengemas [7]. Pengendalian putaran motor stepper juga telah dilakukan dengan sistem kontrol PID pada mesin automatic feeding [8]. Putaran motor penggerak konveyor pada 
mesin line plastic packing juga dapat di kendalikan dengan menggunakan mikrokontroller ATMEGA 386 [9].

Penelitian ini dilakukan dengan tujuan merancang dan membuat sistem kendali kecepatan putar motor pada mesin cnc laser cutting sehingga dapat meningkatkan kinerja dari mesin laser ini dan mendapatkan konfigurasi pemotongan yang tepat untuk material akrilik dari pengujian mesin cnc laser cutting yang dibuat.

\section{METODOLOGI PENELITIAN}

Data proses deasin dan implementasi sistem kontrol kecepatan mesin cnc laser cutting dapat dilihat diagram alir sebagai pada gambar 1 .

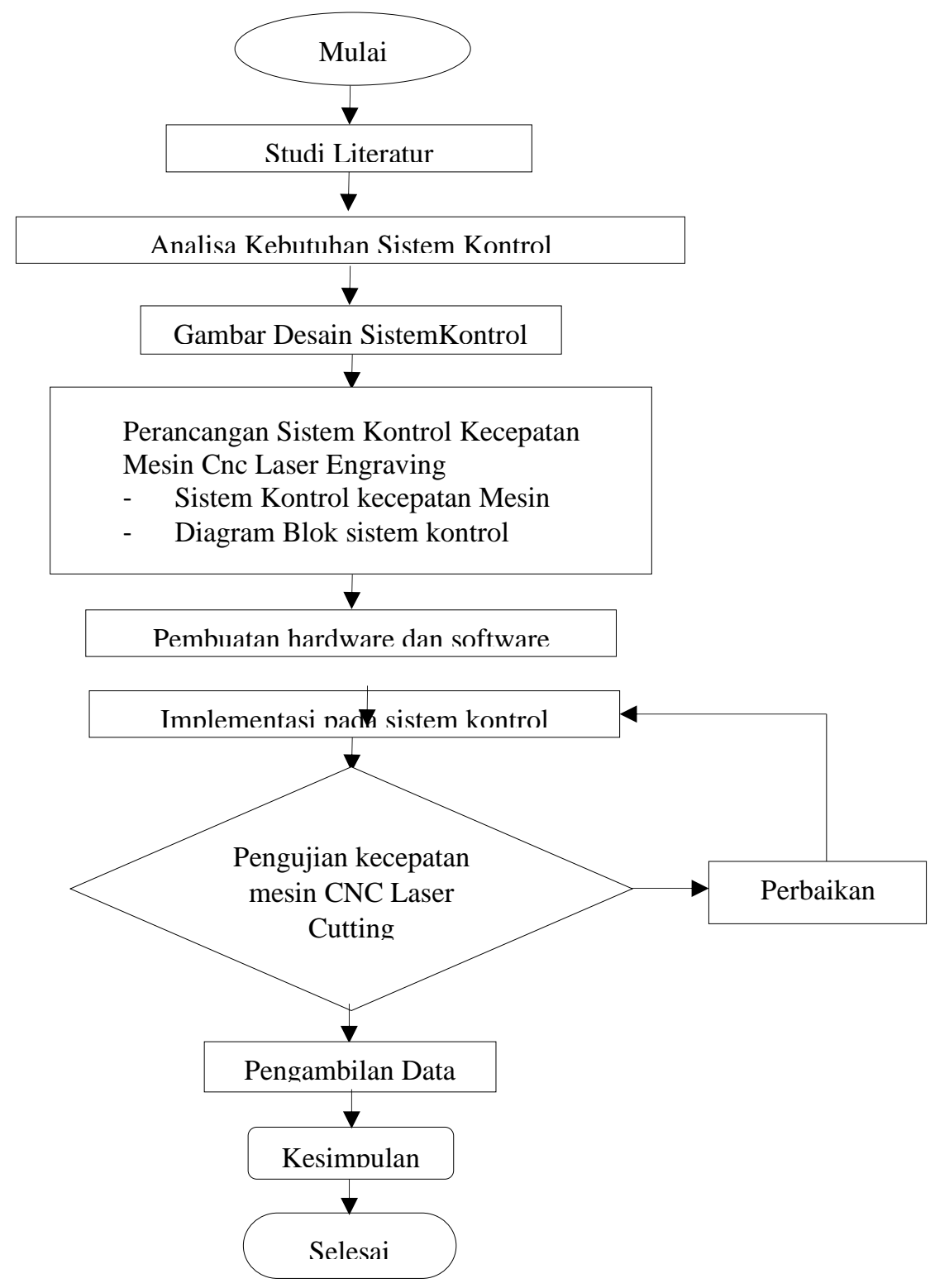

Gambar 1. Diagram Alur Kontrol kecepatan 
Studi literatur meliputi pencarian dan pembelajaran bahan pustaka yang berkaitan dengan segala permasalahan mengenai perancangan desain sistem kontrol kecepatan yang diperoleh dari berbagai sumber antara lain buku, publikasi ilmiah, dan survey mengenai komponen - komponen standart maupun material yang ada dipasaran. Didalam studi literatur ini juga dilakukan observasi lapangan secara langsung mengenai mesin cnc laser cutting yang sudah ada di pabrik .Melalui penelitian ini peneliti menggali informasi dari peneliti - peneliti sebelumnya sebagai perbandingan, baik mengenai kekurangan atau kelebihan yang sudah ada. Selain itu peneliti juga menggali informasi dari buku maupun jurnal penelitian untuk mendapatkan suatu informasi yang ada sebelumnya tentang teori yang berkaitan dengan judul yang digunakan untuk memperoleh landasan ilmiah.

\section{HASIL DAN PEMBAHASAN}

\subsection{Analisa Kebutuhan Sistem Kontrol}

Proses desain dan perancangan sistem kontrol analisa kebutuhan sistem kontrol mesin harus memenuhi beberapa aspek yaitu :

\section{Aspek desain}

Aspek desain sistem kontrol meliputi perhitungan ketepatan gerak motor pada lead screw, desain sistem kontrol lup terbuka, proses pembuatan sistem kontrol dan komponen yang digunakan relatif mudah di dapat dan murah, dan perawatan sistem kontrol yang relatif mudah dan murah.

\section{Aspek manufaktur}

Kontruksi perangcangan sistem kontrol pembuatan box sistem kontrol agar komponen kelistrikan harus tertata rapi. Perancangan mekanisme pengaturan putaran motor. Kebutuhan komponen sistem kontrol meliputi arduino nano, power supply, driver, kabel, dan motor stepper.

\section{Aspek teknik}

Aspek teknik yaitu tentang cara kerja komponen yaitu, motor stepper sumbu X berputar menggerakkan lead screw pada saat sumbu X bergerak, motor stepper sumbu $\mathrm{Y}$ menggerakkan lead screw pada saat sumbu Y bergerak dan menggerakkan meja kerja, motor stepper sumbu $\mathrm{Z}$ menggerakkan lead screw pada saat sumbu $\mathrm{Z}$ diperintahkan untuk bergerak.

\section{Aspek keselamatan kerja}

Keselamatkan kerja diperuntukkan dalam melakukan pekerjaan dan juga dengan memlilih jenis material sistem kontrol yang digunakan bersifat aman dan tidak membahayakan. Catu daya pada sistem kontrol diletakkan pada box yang telah disesuiakan dengan desain mesin.

\subsection{Proses Perancangan Sistem kontrol}

\subsubsection{Sistem Gerak Pada Mesin Laser Cutting}

Lead screw digerakkan motor stepper yang dihubungkan oleh flexible couple mekanismenya dapat digambarkan seperti gambar 2. Dibawah ini :

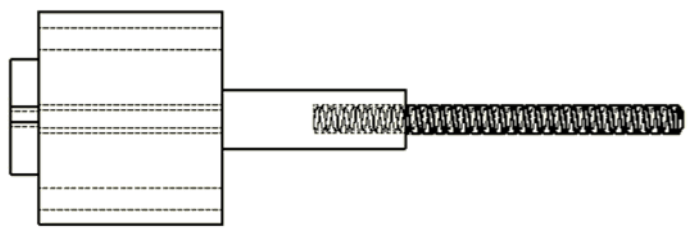

Gambar 2. Mekanisme gerak lead screw 
1. Gaya yang dibutuhkan untuk menggerakkan lead screw di hitung menggunakan persamaan 1 .

$$
F=W+F k \operatorname{Cos} a+N \operatorname{Cos} a
$$

Dimana m adalah massa lead screw $(\mathrm{kg}), \mathrm{g}$ adalah percepatan gravitasi $\left(\mathrm{m} / \mathrm{s}^{2}\right)$.

2. Torsi beban ini didasarkan pada data sebagaiman persamaan 2.[7]

$$
T=\frac{F \times d_{m}}{2}\left(\frac{1 \times \mu \times d_{m}}{\pi \times d_{m}-\mu \times 1}\right)
$$

Dimana T adalah torsi (N.m), F adalah gaya (N), dan d adalah dimeter lead screw (m).

3. Momen inersia untuk menggerakkan lead screw didapatkan persamaan 3 berikut.

$$
J=\frac{T_{b}}{a}
$$

Dimana $\mathrm{J}$ adalah momen inersia $\left(\mathrm{kg} \cdot \mathrm{m}^{2}\right), T_{b}$ adalah torsi beban lead screw, dan a adalah percepatan sudut $(\mathrm{Nm})$.

Hasil perhitungan gaya putar lead screw ditunjukkan pada tabel 1.

Tabel 1. Perhitungan gaya torsi an inersia Lead screw

\begin{tabular}{ccc}
\hline Gaya & Torsi & Inersia \\
$\mathrm{F}(\mathrm{N})$ & $\mathrm{T}(\mathrm{N} . \mathrm{m})$ & $\mathrm{J}\left(\mathrm{kg} . \mathrm{m}^{2}\right)$ \\
\hline $14,328 \mathrm{~N}$ & 0,038027 & 0,00044502 \\
\hline
\end{tabular}

\subsubsection{Analisa pergerakan motor stepper}

1. Unruk menghitung putaran motor dapat menggunakan persamaan 4 berikut :

$$
\omega_{1}=\omega_{2}
$$

Dimana $\omega_{1}$ adalah kecepatan putar motor dan $\omega_{2}$ kecepatan putar lead screw.

2. Hubungan antara electromotive force dapat dihasilkan persamaan 5 [7] :

$$
E_{b}=K_{E} \cdot \omega
$$

Dimana $E_{b}$ adalah electromotive force (volt), $\omega$ adalah kecepatan putaran (rpm), $K_{E}$ adalah Konstanta tegangan.

3. Hubungan tegangan dan arus pada motor stepper dengan persamaan 6 berikut [7]:

$$
V(t)=L \frac{d l(t)}{d t}+R I(t) E_{b}
$$

Dimana $\mathrm{V}(\mathrm{t})$ adalah tegangan (volt), L adalah induktansi koil $(\mathrm{H}), \mathrm{R}$ adalah hambatan (ohm), I adalah arus (A), dan $E_{b}$ adalah electromotor force (volt).

4. Bila pada motor stepper medan magnet konstan maka arus yang dihasilkan proposional dengan torsi :

$$
T=K_{T} I
$$


Dimana $\mathrm{T}$ adalah torsi motor $(\mathrm{kg}-\mathrm{m}){ }_{3} K_{T}$ adalah konstanta torsi (Nm/A), I adalah arus (A).

5. Hubungan kecepatan putaan pulsa untuk menggerakkan motor stepper dapat ditentukan persamaan 8 berikut [8] :

$$
f=\frac{N \cdot n}{60}
$$

Dimana $f$ adalah frekuensi (Hz), $N$ adalah jumlah step, $n$ adalah kecepatan putaran (rpm). Hasil perhitungan ditentukan persamaan berikut.

Tabel. 2 Perhitungan pergerakan motor stepper

\begin{tabular}{ccccc}
\hline$\omega 1(\mathrm{rpm})$ & $\mathrm{Eb}($ volt $)$ & $\mathrm{V}(\mathrm{t})($ volt $)$ & $\mathrm{T}(\mathrm{kg}-\mathrm{m})$ & $f(\mathrm{~Hz})$ \\
\hline 200 & 14,12 & 50,429 & 2,62 & 666,6
\end{tabular}

\subsection{Pemodelan dan simulasi}

Perancangan pengendali kecepatan motor stepper yang dilakukan tanpa menggunakan kontroler PID yaitu dilakukan dengan sistem lup terbuka. Model simulasi pengendali kecepatan motor stepper dengan sistem lup terbuka terlihat pada gambar. 3 :

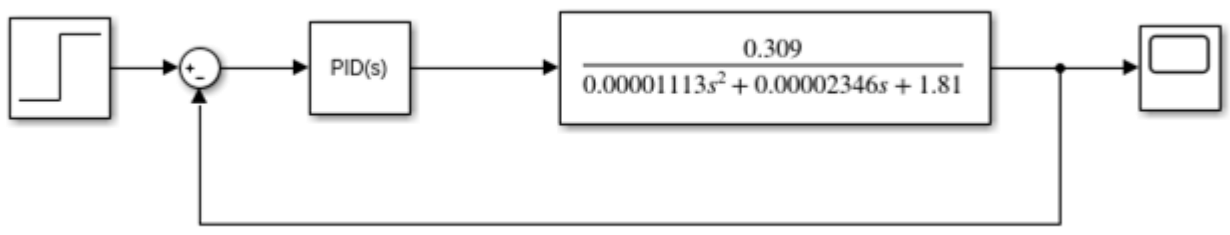

Gambar.3 Diagram Blok sistem kontrol PID

Dalam melakukan simulasi menggunakan matlab didapatkan respon langkah sistem kontrol PID seperti gambar. 4 dibawah ini :

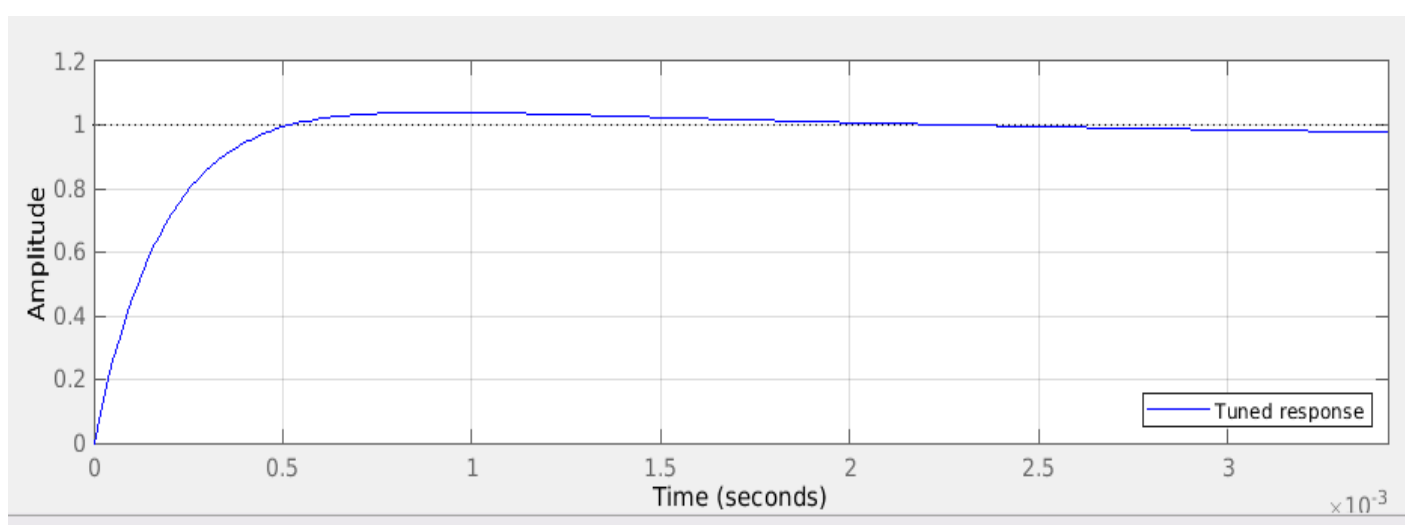

Gambar. 4 Respon langkah sistem kontrol PID

Respon langkah sistem kontrol PID menunjukkan rise time 0,0003 detik, overshoot 3,98 \% dan settling 0,01 detik. 


\subsection{Desain Sistem Kontrol}

Desain sistem kontrol ini menunjukkan cara kerja sistem kontrol putaran motor stepper bermula dari power supply yang mengubah arus AC menjadi DC dihubungan dengan mikrokontroler, kemudian program dari komputer akan memberikan bahasa program ke mikrokontroler yang kemudian driver motor akan memberikan sinyal ke motor stepper sumbu X Y dan $\mathrm{Z}$ dimana tiap sumbu akan aktif untuk menggerakan lead screw masing masing sumbu. Desain sistem kontrol mesin CNC laser menggunakan sistem lup terbuka yang bisa dilihat pada gambar 3 berikut :

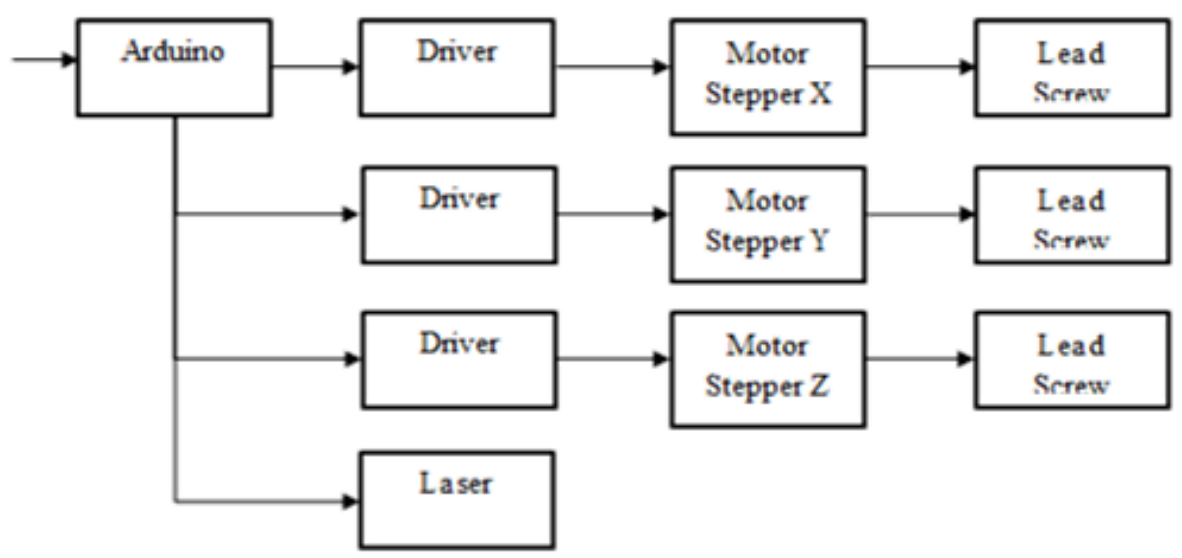

Gambar. 5 Desain sistem kontrol mesin CNC laser

Desain sistem kontrol kecepatan motor diawali dengan input sinyal mikrokontroler berupa tegangan 5v. Mikrokontroler memberikan sinya ke driver motor untuk mengaktifkan motor stepper pada tiap sumbu dengan pulsa 666 per detik dan kecepatan putar motor $200 \mathrm{rpm}$.

\subsection{Desain Instalasi Hardware Sistem Kontrol}

Pada gambar 4 menunjukkan desain instalasi hardware yang diawali dari listrik yang dikonversi dari AC ke DC oleh power supply. Pengoprasian sistem dari komputer melaui software yang menghasilkan G-code dan selanjutnya dibaca oleh mikrokontroler. Kemudian arduino mengkonversi berbagai macam peringtah meliputi power supply mengubah AC menjadi DC kemudian dihubungkan ke mikrokontroler, mikrokontroler memberi sinya ke driver motor dan diterima oleh motor stepper pada setiap sumbu yang diberi sinyal dan mikrokontroler memberi sinya ke laser untuk perintah pemotongan. 


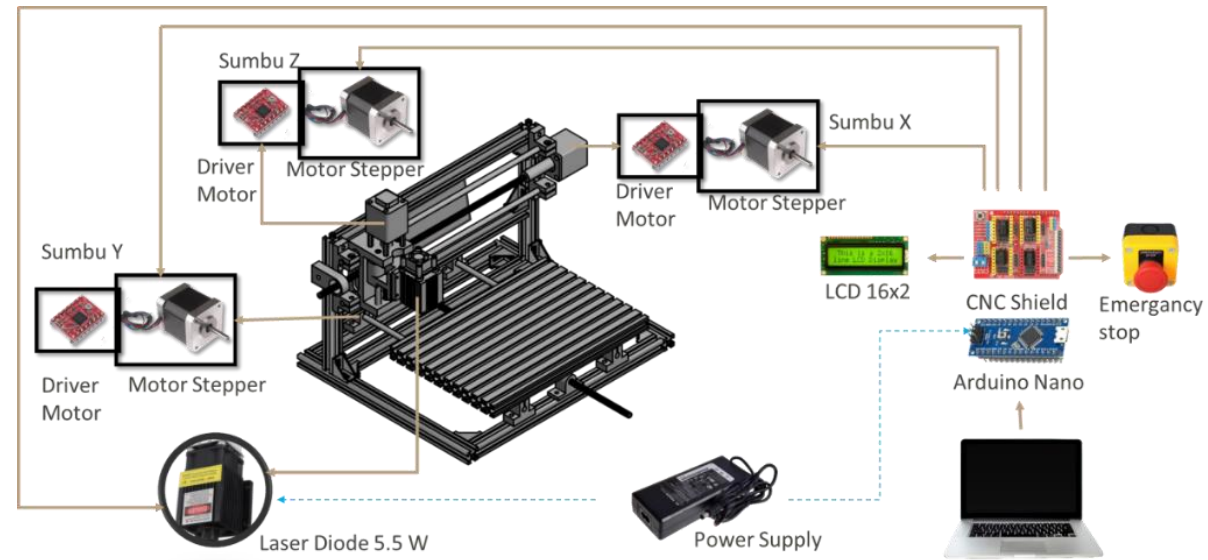

Gambar. 6 Desain Instalasi Hardware

\subsection{Alat untuk Pembuatan dengan Arduino Nano}

Alat yang digunakan pada sistem kontrol kecepatan mesin CNC laser meliputi komputer, arduino nano, motor stepper, CNC shield, driver motor, kabel jamper, dan power supply.

\subsection{Hasil Pembuatan Hardware}

Hasil pembuatan hardware dapat dilihat pada gambar 5. Yang menjelaskan hasil pembuatan hardware yang meliputi mikrokontroler arduino nano, $\mathrm{CNC}$ shield, driver motor, lcd, dan power supply berada di dalam box.

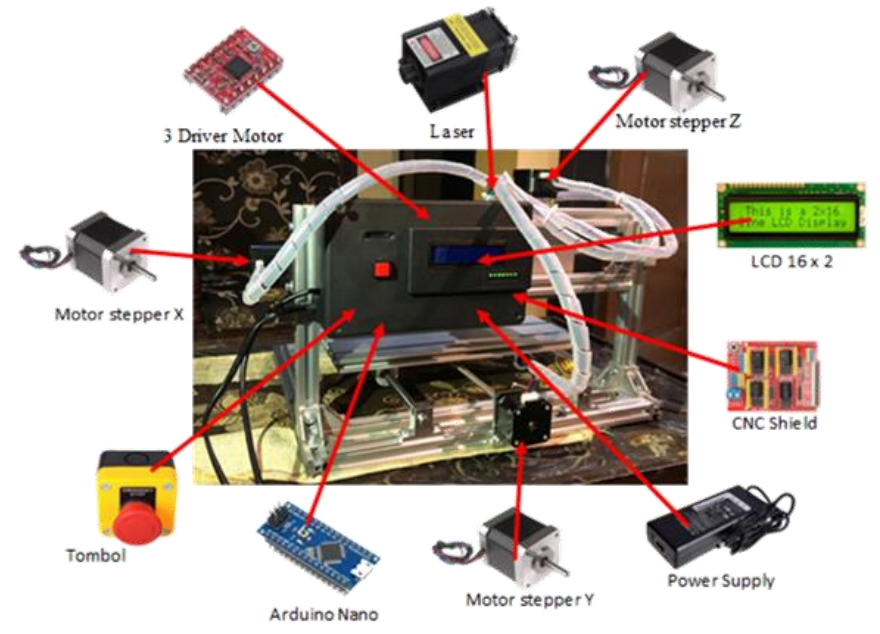

Gambar. 7 Hasil pembuatan hardware

\subsection{Hasil Pembuatan Hardware didalam Box}

Hasil pembuatan rangkaian di dalam box kontrol ditunjukkan pada gambar 8 . Terdiri dari power supply, driver motor, mikrokontroler. 


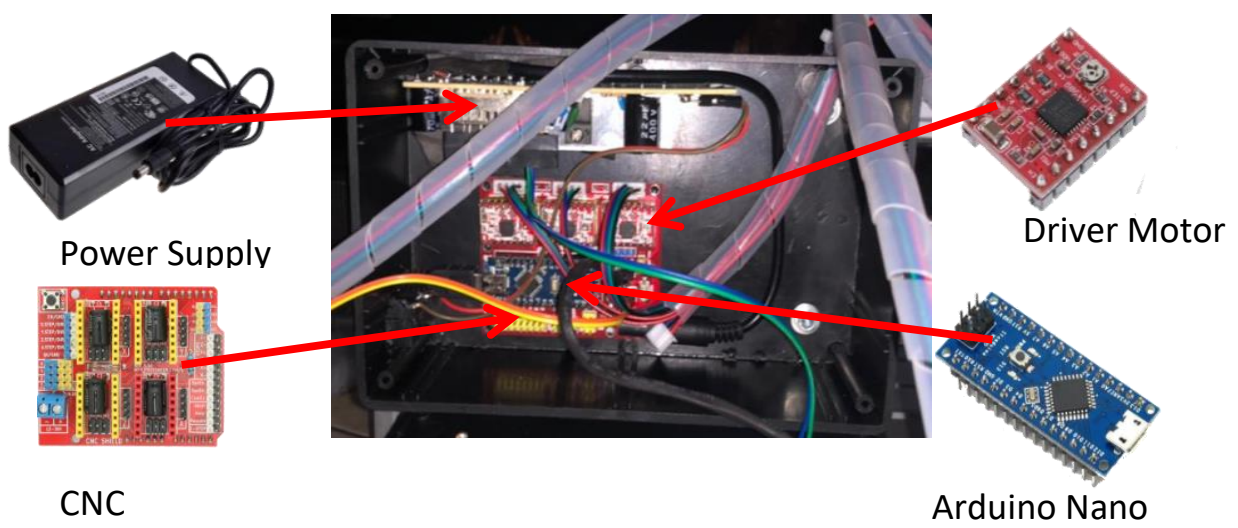

\section{Gambar. 8 Box Sistem Kontrol}

\subsection{Pengujian Sistem Kontrol}

Pengujian sistem kontrol untuk menguji putaran motor stepper untuk pemotongan akrilik 3 $\mathrm{mm}$ dengan panjang $80 \mathrm{~mm}$ dilakukan sebanyak 4 kali dapat dilihat pada tabel 4 berikut :

Tabel 4 Hasil Pengujian

\begin{tabular}{ccccc}
\hline No & $\begin{array}{c}\text { Settingan } \\
\text { Putaran (rpm) }\end{array}$ & $\begin{array}{c}\text { Waktu pengerjaan } \\
\text { (menit) }\end{array}$ & $\begin{array}{c}\text { Akurasi putaran } \\
\text { motor }\end{array}$ & eror \\
\hline 1 & 200 & 180 & 198 & 1,01 \\
\hline 2 & 200 & 180 & 201 & 0,99 \\
\hline 3 & 200 & 180 & 201 & 0,99 \\
\hline 4 & 200 & 180 & 201 & 0,99 \\
\hline
\end{tabular}

Hasil pengujian yang didapat sesuai tabel diatas ketika putaran motor disetting $200 \mathrm{rpm}$ waktu pengerjaan 180 menit didapatkan akurasi putaran rata-rata 200,25 rpm dan didapatkan nilai error rata-rata sebesar $0,995 \%$.

\section{KESIMPULAN}

Berdasarkan penelitian telah di rancang dan dibuat sistem kontrol kecepatan gerak motor stepper pada mesin CNC laser dengan menggunakan sistem kontrol PID ddengan nilai $\mathrm{P}=$ $85,7095, \mathrm{I}=8786,01, \mathrm{D}=0,2090$ hasil pengujian menunjukkan putaran motor motor stepper menunjukkan kecepatan motor 200 rpm dan didapatkan akurasi putaran motor 200,25 rpm dengan nilai error rata-rata sebesar $0,995 \%$.

\section{DAFTAR PUSTAKA}

[1] M. Munadi, A. Syukri, J. D. Setiawan, and M. Ariyanto, 2018, Rancang-bangun prototipe mesin CNC laser engraving dua sumbu menggunakan diode laser, J. Tek. Mesin Indonesia., vol. 13, no. 1, p. 32, 2018, doi: 10.36289/jtmi.v13i1.88.

[2] Kushartanto P., Kabib M., Winarso R. ,2019, Sistem kontrol gerak dan perhitungan produk pada mesin pres dan pemotong kantong plastik, Jurnal crankshaft, vol. 2, no. 1, pp. $57-66$. 
[3] S. Rahman, Helmi, F. Rahmad, Iwan, and A. Saleh, "Perancangan Mesin Cnc ( Computer Numericaly Control ) Mini Plotter Berbasis Arduino," IT J., vol. 5, no. 2, pp. 152-161, 2017.

[4] G. Kahl, 2015, L aser- c apture m icrodissection (LCM), Dict. Genomics, Transcr. Proteomics, vol. 15, no. 01, pp. 1-10, doi: 10.1002/9783527678679.dg06699.

[5] Irwanto, B., Kabib, M. and Winarso, R., 2019, Rancang Bangun Sistem Kontrol Penimbangan Tembakau Dengan Mikrokontroller Arduino Uno, Jurnal Crankshaft, Volume 2, No. 1, pp. 27-32. doi: 10.24176/crankshaft.v2i2.3837.

[6] A. Fendri, Implementasi Mini CNC Router 3 Axis untuk Pembuatan Huruf dan Gambar Berbasis," vol. 3, no. 1, pp. 95-102, 2019.

[7] S. B. Lutfi, M. Kabib, and T. Hidayat, Desain Dan Implementasi Sistem Kontrol Putaran Rol Penarik Dan Pengepres Plastik Pada Mesin Pengemas Jahe Bubuk, Jurnal Crankshaft, vol. 2, no. 2, pp. 41-50, 2019, doi: 10.24176/crankshaft.v2i2.3864.

[8] Kabib M., 2008, Analisa dan Pengembangan Sistem Kontrol pada Mesin Automatic Feeding untuk Proses $U$ bending, Thesis,Program Studi Teknik Mesin, ITS., doi10.13140/RG.2.2.36022.45121.

[9] Huda S., Kabib M., Winarso R., 2017, Desain Automatic Line Plastic Packing of Cake Berbasis Mikrokontroler ATMEGA 328, Seminar SNATIF ke 3, Fakultas Teknik UMK, pp. 577-584 